Esta revista forma parte del acervo de la Biblioteca Jurídica Virtual del Instituto de Investigaciones Jurídicas de la UNAM

\title{
Corte Interamericana de Derechos Humanos y pobreza. Nuevas incursiones a la luz del caso Hacienda Brasil Verde
}

Inter-American Court of Human Rights and Poverty. New Incursions in the Light of the Case Hacienda Brasil Verde

\author{
Cour Interamericaine des Droits de l'Homme \\ et la pauvrete. Nouvelles incursions a la lumiere \\ de l'affaire Hacienda Brasil Verde
}

\author{
Ruth MARTINÓN* \\ Isabel WENCES**
}

SUMARIO: I. Introducción. II. Descripción del caso Trabajadores de la Hacienda Brasil Verde vs. Brasil. III. Análisis de aspectos clave de la sentencia: contexto, grupo vulnerable, discriminación estructural y responsabilidad estatal. IV. Examen crítico y aportaciones. V. Bibliografía.

* Profesora en el área de derecho internacional público y relaciones internacionales, en la Universidad de La Laguna, y directora de su Centro de Documentación Europeo.

** Licenciada y maestra en ciencia política por la UNAM y doctora en derechos fundamentales por la Universidad Carlos III de Madrid, donde es profesora titular.

Artículo recibido el 2 de enero de 2019 Aprobado para publicación el 3 de octubre de 2019 
RESUMEN: Desde los años noventa en el ámbito internacional se han sucedido los intentos de aunar la lucha contra la pobreza y la defensa de los derechos humanos. Hasta ahora, ello se ha llevado a cabo a través de instrumentos programáticos o de soft law. La Corte IDH dio un giro a esta tendencia con su fallo del caso Trabajadores de la Hacienda Brasil Verde vs. Brasil, donde se concreta la juridificación del vínculo entre pobreza y derechos humanos. El objetivo principal de este trabajo es advertir sobre la envergadura que, en el marco de los esfuerzos por erradicar la pobreza, supone este paso. Para conseguir dicho objetivo, analizamos cómo el Tribunal Interamericano realiza esa construcción que culmina determinando la responsabilidad estatal por violación de derechos humanos con relación al principio de igualdad y no discriminación por posición económica, junto a las consecuencias de dicho razonamiento, especialmente para la identificación de nuevos estándares judiciales en materia de lucha contra la pobreza.

Palabras clave: pobreza, derechos humanos, Corte IDH, grupo vulnerable, discriminación estructural

ABSTRACT: Since the nineties the international arena has born witness to a number of attempts to join the forces against poverty to the defense of human rights. Such a task has been founded so far on programmatic or soft law instruments. The Inter-American Court gave a twist to this trend with its ruling in the Case Workers of the Hacienda Brasil Verde vs. Brazil, because it established the juridification of the link between poverty and human rights. The main objective of this research is to unveil the importance of this step in the context of the efforts to eradicate poverty. With this objective in mind, we analyze how the Inter-American Court accomplishes this construction that culminates by determining state responsibility for violation of human rights in relation to the principle of equality and non-discrimination by economic position, together with the consequences of this reasoning, especially for the identification of new judicial standards in the struggle against poverty.

Key words: Poverty, Human Rights, Inter-American Court of Human Rights, Vulnerable Group, Structural Discrimination

RÉSUMÉ: Depuis les années 1990, sur la scène internationale, les tentatives d'unifier la lutte contre la pauvreté et la défense des droits de l'homme s'effectuaient par le biais d'instruments de caractère programmatique ou de soft law. La Cour interaméricaine a donné à cette tendance une nouvelle tournure par sa sentence dans l'affaire Trabajadores de la Hacienda Brasil Verde vs Brasil, dans laquelle se concrétise le caractère juridictionnel du lien entre pauvreté et droits de l'homme. L'objectif principal de ce travail est de signaler l'importance que, dans le cadre des efforts visant à éradiquer la pauvreté, ce changement signifie. Pour atteindre cet objectif, nous analysons comment la Cour interaméricaine réalise cette construction qui culmine dans la détermination de la responsabilité de l'État devant la violation des droits de l'homme en ce qui concerne, d'une part, le principe de l'égalité et de la non-discrimination pour position économique, et d'autre part, les conséquences d'un tel raisonnement pour l'identification de nouvelles normes juridiques dans la lutte contre la pauvreté.

Mots-clés: pauvreté, droits de l'homme, Cour Interaméricaine des Droits de l'Homme, groupe vulnérable, discrimination structurale 


\section{INTRODUCCIÓN ${ }^{1}$}

El primero de los objetivos de desarrollo sostenible de la Agenda 2030 del Programa de las Naciones Unidas para el Desarrollo (PNUD) es el de erradicar la pobreza. Esta lucha se debe dar desde todos los frentes posibles, aquí optamos por uno de ellos, el del derecho internacional de los derechos humanos. En concreto, el objetivo de este trabajo es mostrar el hito que supone la sentencia del caso Hacienda Brasil Verde vs. Brasil de la Corte Interamericana de Derechos Humanos, ${ }^{2}$ en la medida en que aporta un vínculo entre pobreza y derechos humanos en un instrumento jurídicamente vinculante, que abre una puerta fundamental para la juridificación de dicha relación.

La Declaración Universal de Derechos Humanos, tras proclamar en su preámbulo el advenimiento de un mundo en el que los seres humanos fuesen liberados del temor y la miseria, considera que hay una serie de derechos de carácter social y económico que son indispensables para la dignidad y el libre desarrollo de la personalidad. ${ }^{3}$ Sin embargo, el devenir posterior del derecho internacional de los derechos humanos acabó escindiendo el movimiento de los derechos humanos y el de lucha contra la pobreza. Deriva que fue confirmada por la aprobación en dos tratados distintos con diferentes sistemas de protección, por un lado, el Pacto Internacional de los Derechos Civiles y Políticos, y por el otro, el Pacto Internacional de los Derechos Económicos, Sociales y Culturales.

Fue a partir de la década de los años noventa, tras el final de la guerra fría, en particular desde la proclamación de la indivisibilidad e interdependencia de todos los derechos en la Conferencia Mundial de Derechos Humanos, celebrada en Viena en 1993, cuando cobró relevancia la relación entre po-

1 El presente artículo se ha desarrollado en el marco del proyecto de investigación "Jueces en democracia. La filosofía política de la Corte Interamericana de Derechos Humanos”, financiado por el Ministerio de Economía, Industria y Competitividad (España). Referencia: DER2016-79805-P (AEI/FEDER, UE), en el que ambas investigadoras participan.

2 De ahora en adelante Corte IDH o Tribunal Interamericano.

3 Entre ellos, los derechos económicos, sociales y culturales (artículo 22); el derecho al trabajo (artículo 23); el derecho a la educación (artículo 26); y el derecho a un nivel de vida adecuado (artículo 25). 
breza y derechos humanos. ${ }^{4}$ Poco tiempo después, en 1997, el secretario general de Naciones Unidas, Kofi Annan, estableció la necesidad de integrar el programa de derechos humanos "en toda la gama de las actividades de la Organización" y sus diferentes organismos desarrollaron distintas perspectivas de vinculación entre pobreza y derechos humanos. Destaca la labor de la Relatoría Especial Sobre Extrema Pobreza y Derechos Humanos ${ }^{6}$ que, en 2012, presentó los Principios Rectores sobre la misma materia. ${ }^{7}$

En el Sistema Interamericano de Derechos Humanos (SIDH), la Comisión Interamericana de Derechos Humanos (CIDH) comenzó su acercamiento a este ámbito mostrando la necesidad de dar mayor importancia a los Derechos Económicos, Sociales y Culturales (DESC), para los que creó una Unidad Temática en 2012 y una Relatoría Especial en 2014. ${ }^{8}$ Precisamente, dicha Unidad sobre los DESC fue la encargada de la coordinación del Informe Sobre Pobreza y Derechos Humanos en las Américas, publicado en 2017. En este trabajo, se afirma que la pobreza constituye una violación generalizada a todos los derechos humanos, tanto civiles y políticos como sociales, económicos y culturales y que obstaculiza el goce y ejercicio de los derechos humanos, en condiciones de igualdad real, por parte de quienes viven en dicha situación, lo cual es muestra de una concepción clara de la indivisibilidad e interdependencia de todos los derechos. ${ }^{9}$ Uno de los objetivos centrales del Informe es la consolidación y el desarrollo de estándares

4 La Declaración y Programa de Acción de la Conferencia Mundial de Derechos Humanos, celebrada en Viena en 1993, señala en su punto quinto: "Todos los derechos humanos son universales, indivisibles e interdependientes y están relacionados entre si”."

5 Naciones Unidas, Renovación de las Naciones Unidas: un programa de reforma, Informe del Secretario General, A/51/950, 14 de julio, 1997, párr. 79.

6 Esta surgió en 2011 (A/HRC/RES/17/13) como continuación de la labor desarrollada por la figura del experto especial para la extrema pobreza y derechos humanos creado en 1998 (E/DEC/1998/250).

7 Aprobados por el Consejo de Derechos Humanos de Naciones Unidas (A/HRC/21/39).

8 La importancia de esta Relatoría Especial sobre Derechos Económicos, Sociales, Culturales y Ambientales es que "visibiliza en un sistema tradicionalmente de derechos de "primera generación”, derechos que podrían ayudar a combatir situaciones de carácter estructural, como las de pobreza y la exclusión social que, sin lugar a dudas, tienen sus raíces en la falta de realización de ciertos DESCA”. Ferrer Mac-Gregor, Eduardo, La justiciabilidad de los derechos económicos, sociales, culturales y ambientales en el Sistema Interamericano de Derechos Humanos, México, UNAM-CNDH, 2017, p. 205.

9 Comisión Interamericana de Derechos Humanos, Informe sobre pobreza y derechos humanos en las Américas, OEA/Ser.L/V/II.164. Doc. 147, 2017, p. 11. 

que permitan al derecho internacional proveer un marco "normativo explícito e imperativo que guíe u oriente la formulación de políticas y estrategias nacionales" contra la pobreza, llegando a considerar que, en determinados supuestos, la pobreza podría implicar violaciones de derechos humanos "atribuibles a la responsabilidad internacional del Estado". ${ }^{10}$

En cuanto a la definición de estándares interamericanos en materia de pobreza y pobreza extrema, considerando que a la fecha ni la Comisión ni la Corte IDH han desarrollado plenamente los mismos mediante informes o jurisprudencia específicos y sistemáticos, este Informe puede constituir un importante paso histórico, por ser la primera vez que la CIDH desarrolla en detalle las obligaciones internacionales de los Estados para enfrentar la situación de pobreza desde un enfoque de derechos humanos.

Ahora bien, todavía es necesario, por un lado, mejorar la concreción de la relación entre pobreza y derechos humanos, aclarando las obligaciones y los derechos, con los titulares de los mismos, así como los mecanismos y estándares que pueden permitir hacer valer el potencial jurídico y jurisdiccional de dicha relación; y, por el otro, avanzar en un enfoque de mirada amplia de la pobreza, donde se contemple el desarrollo y satisfacción de necesidades y el desarrollo y aplicación de capacidades, con el establecimiento de medidas acordes de reparación y, consecuentemente, de políticas públicas.

Es verdad que, a lo largo de los últimos años, la Corte IDH ha ido dando pasos significativos, de manera indirecta, a través de la consideración cada vez mayor de los DESC, bien a través de la posibilidad explícita abierta por el artículo 19.6 del Protocolo de San Salvador; bien a través de la técnica de la conexión; o bien, de manera más reciente, haciendo uso del artículo 26 de la Convención Americana de Derechos Humanos (CADH). ${ }^{11}$ Después de años de reticencia jurisprudencial (salvo lo sostenido en algunos votos

10 Ibidem, pp. 15 y 42, respectivamente.

11 Para un recorrido sobre la evolución del tratamiento de los DESCA en la jurisprudencia de la Corte IDH, véase Aguirre Castro, Pamela Juliana, "Los derechos económicos, sociales y culturales a la luz de la jurisprudencia de la Corte Interamericana de Derechos Humanos", Revista Interamericana de Derechos Humanos, vol. 67, 2018. 

particulares), ${ }^{12}$ en $2017^{13}$ se aceptó la justiciabilidad directa y autónoma de los DESC a través del artículo 26 de la $\mathrm{CADH}$, con todas las ventajas que ello comporta. ${ }^{14} \mathrm{Si}$ bien es cier to que no se ha utilizado esta posibilidad para abordar la relación entre pobreza y derechos humanos, no cabe duda que crea una vía posible para ello.

Sin embargo, un cambio sustantivo ya tuvo lugar en octubre de 2016 con la sentencia Trabajadores de la Hacienda Brasil Verde vs. Brasil, donde la Corte IDH da un giro y aborda el tratamiento de la pobreza de manera directa. ${ }^{15}$ Antes de dicha sentencia, el Tribunal Interamericano sólo había "identificado la pobreza como un factor de vulnerabilidad que profundiza el impacto que tienen las víctimas de violaciones a derechos humanos sometidas a esta condición”. ${ }^{16}$ En concreto, se ha asociado la pobreza a grupos vulnerables tradicionalmente identificados (niños, mujeres, indígenas, discapacitados, migrantes...) como agravantes de su vulnerabilidad. Rara vez la pobreza ha sido tratada como causante de vulnerabilidad en sí misma ${ }^{17}$ y no con suficiente identidad como para identificarla con la posición económica como categoría prohibida de discriminación y condenar al Estado por ello. La

12 Véase, por todos, Voto concurrente de la jueza Margarette May Macaulay en el caso Furlan y Familiares vs. Argentina, Corte IDH. Excepciones preliminares, fondo, reparaciones y costas, sentencia del 31 de agosto de 2012, serie C, núm. 246.

13 Corte IDH, caso Lagos del Campo vs. Perú. Excepciones preliminares, fondo, reparaciones y costas, sentencia del 31 de agosto de 2017, serie C, núm. 340. Se declaró la vulneración del derecho a la estabilidad laboral sobre la base del artículo 26, CADH.

14 Rivera Basulto, Marcela Cecilia, "Justiciabilidad directa de los derechos económicos, sociales, culturales y ambientales. Después de Lagos del Campo, ¿qué sigue?”, Revista Interamericana de Derechos Humanos, vol. 67, 2018, pp. 134-139.

15 Corte IDH, Caso Trabajadores de la Hacienda Brasil Verde vs. Brasil. Excepciones preliminares, fondo, reparaciones y costas. Sentencia del 20 de octubre de 2016. Serie C, núm. 318. De ahora en adelante caso Hacienda Brasil Verde. Otra sentencia, más reciente aún, también constituye un hito histórico en la jurisprudencia de la Corte IDH ya que interpreta de manera directa lo dispuesto en la CADH a través de su artículo 26 y da contenido al derecho al trabajo, como un derecho exigible. Nos referimos a: Corte IDH, Caso Lagos del Campo vs. Perú. Excepciones preliminares, fondo, reparaciones y costas. Sentencia de 31 de agosto de 2017. Serie C, núm. 340. Con ello se dan pasos significativos hacia una justiciabilidad directa de los derechos económicos, sociales, culturales y ambientales.

16 Voto razonado del juez Eduardo Ferrer Mac-Gregor, Caso Trabajadores de la Hacienda Brasil Verde vs. Brasil, párr. 26.

17 Corte IDH, caso Uzcátegui y otros vs.Venezuela. Fondo y reparaciones, sentencia del 3 de septiembre de 2012, serie C, núm. 249, párr. 204. 
Sentencia de la Corte IDH referida al caso Hacienda Brasil Verde considera a Brasil responsable de la violación del derecho a no ser sometido a servidumbre, trata y esclavitud, en el marco de una situación de discriminación estructural histórica debido a la posición económica, es decir, la pobreza, de los 85 trabajadores del caso.

Lo que pretendemos en este trabajo es mostrar el punto de inflexión que representa esta sentencia del Tribunal Interamericano en el proceso de incorporación de la pobreza al derecho de los derechos humanos en el SIDH, en la medida en que presenta, en una decisión jurídicamente obligatoria, una vinculación directa entre pobreza y derechos humanos. El alcance de este propósito requiere del desarrollo de dos objetivos secundarios. En primer lugar, analizar la viabilidad y los alcances que, en esta nueva aproximación de la relación entre pobreza y derechos humanos, supone la creación de un nuevo grupo vulnerable, el de los pobres, e indagar cómo la discriminación estructural de dicho grupo puede conllevar la violación del principio de igualdad y no discriminación por posición económica. En segundo lugar, examinamos cómo se concluye la responsabilidad estatal a partir de la determinación de ese grupo vulnerable y de la discriminación estructural. El fin último es desentrañar qué estándares han nacido para la lucha contra la pobreza en el derecho internacional de los derechos humanos. ${ }^{18}$

Para llevar a cabo estos objetivos, el trabajo se encuentra estructurado de la siguiente manera. Bajo el segundo epígrafe se describe el caso y se justifica la importancia del objeto de estudio seleccionado; en el tercer apartado se hace la disección del caso poniendo especial énfasis, por un lado, en la importancia que adquiere el análisis del contexto; por el otro, en el grupo vulnerable de los pobres y en la discriminación por razón de posición económica; y, finalmente, en la responsabilidad estatal. El cuarto apartado

18 En el ámbito del Consejo de Europa, el Tribunal Europeo de Derechos Humanos ha introducido los DESC por conexión, y el Comité Europeo de Derechos Sociales ha emitido conclusiones específicamente vinculadas al artículo 30 de la Carta Social Europea Revisada, de 1996, en la cual se recoge el derecho a la protección contra la pobreza y la exclusión social, disponible en: https://www.coe.int/en/web/turin-european-social-charter/european-committee-of-social-rights. El trabajo de este Comité ha permitido hablar de un grupo vulnerable de personas en situación precaria. Véase Jimena Quesada, Luis, "La protección de los grupos vulnerables por el Consejo de Europa”, en Sanz Caballero, Susana (ed.), Colectivos vulnerables y derechos humanos. Perspectiva internacional, Valencia, Tirant lo Blanch, 2010. Sin embargo, en ningún caso hay una sentencia en sentido estricto que responsabilice a un Estado a través de la conexión entre pobreza y violación de derechos humanos. 
Esta revista forma parte del acervo de la Biblioteca Jurídica Virtual del Instituto de Investigaciones Jurídicas de la UNAM

se centra en el análisis de estos elementos y, a modo de conclusión, de su posible repercusión en el derecho internacional de los derechos humanos.

\author{
II. DESCRIPCIÓN DEL CASO TRABAJADORES \\ DE LA HACIENDA BRASILVERDE VS. BRASIL
}

En diciembre de 1988 y enero de 1989 se produjeron las primeras denuncias referidas a la existencia de servidumbre y trabajo esclavo en la Hacienda Brasil Verde, tras las cuales se llevaron a cabo sucesivas visitas de representantes del Estado a la Hacienda. Debido a que el Estado no adoptó medidas razonables de prevención y respuesta ante las evidencias de trabajo forzoso y servidumbre, ni proveyó a las víctimas de mecanismos judiciales efectivos para la protección de sus derechos, se hizo una petición de intervención — en diciembre de 1988 - a la CIDH. Asimismo y considerando que Brasil se adhirió a la CADH el 6 de noviembre de 1992 y reconoció al competencia de la Corte IDH el 10 de diciembre de 1998, sólo entraron en la competencia ratione temporis de la Corte IDH los hechos referidos a las desapariciones forzadas ${ }^{19} \mathrm{y}$

... los supuestos hechos y omisiones del Estado que tuvieron lugar en las investigaciones y procesos relacionados a la inspección realizada en la Hacienda Brasil Verde en 1997, ocurridos con posterioridad al reconocimiento por parte de Brasil de la competencia contenciosa del Tribunal, al igual que los hechos relacionados con la inspección realizada en el año 2000 y los procesos iniciados con posterioridad a ésta. ${ }^{20}$

Los procesos iniciados a raíz de la denuncia de 1997 acabaron con multas irrisorias, suspensiones del procedimiento, declaraciones judiciales de incompetencia y declaración de la acción penal como extinta. ${ }^{21}$ Con base

19 Entre los hechos recogidos en el Informe de Admisibilidad y Fondo de la CIDH, estaba la desaparición forzada de Luis Ferreira da Cruz e Iron Canuto da Silva, como parte de la denuncia presentada en diciembre de 1988 (párrs. 2, y 129), cuyo carácter de acto continuo o permanente ha sido establecido de manera reiterada por el derecho internacional de los derechos humanos (párr. 64).

20 Corte IDH, caso Trabajadores de la Hacienda Brasil Verde vs. Brasil, párr. 65.

21 Ibidem, párrs. 153-161. 

en el artículo 35.2 del Reglamento, la Corte identificó a 43 trabajadores presentes en la Hacienda Brasil Verde durante la fiscalización de 1997 y consideró al Estado responsable de violar las garantías judiciales de debida diligencia y plazo razonable (8.1 CADH) y el derecho a la protección judicial $(25 \mathrm{CADH}){ }^{22}$

En marzo de 2000, dos jóvenes lograron escapar de la Hacienda y denunciaron a la policía la situación de explotación y violencia en que se encontraban. Esto motivó una fiscalización por parte de los inspectores de la Dirección General de Trabajo en compañía de la Policía Federal de Brasil. De dicha inspección resultó un informe que sirvió para fundamentar una acción civil pública ante la justicia laboral contra el propietario de la Hacienda, al considerarse que los trabajadores se encontraban retenidos en un sistema de cárcel privada, realizando trabajos en régimen de esclavitud y viviendo en condiciones de vida degradantes. Asimismo, en el año 2000, el Ministerio Público Federal presentó una denuncia penal, pero el Estado no pudo ofrecer a la Corte IDH más información acerca de este proceso. Finalmente, ninguno de los procedimientos determinó tipo alguno de responsabilidad ni constituyó un medio de reparación de daño a las víctimas. ${ }^{23}$

Dado el perjuicio ocasionado a los 85 trabajadores rescatados en el año 2000, la Corte IDH consideró al Estado responsable por la violación del derecho a no ser sometido a esclavitud y trata de personas (artículo 6.1 de la CADH, en relación con los artículos 1.1, 3, 5, 7, 11 y 22 del mismo instrumento) ${ }^{24}$ por la violación del artículo 6.1 de la CADH, con relación al artículo 1.1 del mismo instrumento, producida en el marco de una situación de discriminación estructural histórica, en razón de la posición económica; y por violar sus derechos a las garantías judiciales de debida diligencia y plazo razonable (artículo $8.1, \mathrm{CADH}$ ) y a la protección judicial (artículo 25, CADH). ${ }^{25}$

No cabe duda de que esta sentencia de la Corte IDH es un hito fundamental en la lucha contra la esclavitud, al poner de manifiesto sus formas contemporáneas. Es el primer caso que llega a la Corte directamente rela-

22 Ibidem, puntos resolutivos 5 y 6 .

23 Ibidem, párrs. 177, 179, 185, 389, 390 y 405.

24 Se está haciendo referencia a los derechos a la personalidad jurídica, la integridad y libertad personales, al derecho a no ser tratado de manera indigna y a la libertad de circulación, lo que muestra el carácter pluriofensivo de la esclavitud.

25 Corte IDH, caso Trabajadores de la Hacienda... cit., puntos resolutivos 3-6. 
cionado con la vulneración del artículo 6.1 de la CADH, el cual establece que: "Nadie puede ser sometido a esclavitud o servidumbre, y tanto éstas, como la trata de esclavos y la trata de mujeres están prohibidas en todas sus formas", lo que llevó al Tribunal Interamericano a ocuparse ampliamente de la prohibición de la esclavitud, servidumbre, trabajo forzoso y prácticas análogas a la esclavitud, así como de la trata de esclavos y mujeres en el derecho internacional contemporáneo. ${ }^{26}$

Sin menoscabo de la importancia que supone la esclavitud denunciada en la sentencia que nos ocupa, en esta ocasión sólo centramos nuestra atención en la identificación de un nuevo grupo vulnerable que sufre discriminación estructural (histórica) debido a su posición económica, esto es, de su pobreza. Una circunstancia que conduce al sufrimiento de graves violaciones de los derechos humanos. Es también la primera vez que, en el contexto del SIDH, se reconoce la pobreza como parte de la discriminación por posición económica establecida en el artículo 1.1. de la $\mathrm{CADH},{ }^{27}$ lo que está ligado a la configuración de un grupo vulnerable conformado únicamente por la condición de pobre, sin necesidad de ligarlo a otros factores.

De hecho, la calificación de una situación de discriminación estructural de carácter histórico supone asimismo una novedad. El juez Ferrer MacGregor destaca, en su voto razonado de la sentencia, que es "el primer caso en donde expresamente la Corte IDH encuentra responsabilidad internacional contra un Estado por perpetuar esta situación estructural histórica de exclusión". ${ }^{28}$

26 Ibidem, párrs. 248-306. Previamente a esta sentencia, la Corte IDH sólo se había ocupado de casos relacionados con trabajo forzoso.

27 Voto razonado del juez Eduardo Ferrer Mac-Gregor, caso Trabajadores de la Hacienda Brasil Verde vs. Brasil, párr. 2.

28 Voto razonado del juez Eduardo Ferrer Mac-Gregor, caso Trabajadores de la Hacienda Brasil Verde vs. Brasil, párr. 84. Precisamente, esta calificación provocó el voto particular parcialmente disidente del juez Sierra Porto por considerar que no se había realizado un análisis suficiente para concluir la existencia de dicha discriminación y que la mera existencia de problemas sociales estructurales o vulnerabilidad no puede generar la responsabilidad internacional del Estado (voto parcialmente disidente del juez Humberto Antonio Sierra Porto, caso Trabajadores de la Hacienda Brasil Verde vs. Brasil, párrs. 6, 8, 10-12). El juez Vio Grossi afirma en su voto individual concurrente que la referencia a la discriminación estructural histórica no implica que se esté declarando, en general, la responsabilidad del Estado en virtud de ella, sino que se trata del contexto que explica, pero no justifica, la discriminación de las víctimas 


\section{ANÁlisis DE ASPECTOS CLAVE DE LA SENTENCIA: CONTEXTO, GRUPO VULNERABLE, DISCRIMINACIÓN ESTRUCTURAL}

Y RESPONSABILIDAD ESTATAL

Delineado el esbozo precedente, entramos al estudio de la elaboración y de los contenidos de la sentencia. Primero expondremos el análisis del contexto que realiza la Corte IDH como paso previo para la determinación de un nuevo grupo vulnerable, el de la pobreza. A continuación, examinamos las razones esgrimidas para crear y vincular este nuevo grupo vulnerable con la discriminación estructural. Por último, mostramos las consecuencias de dicha construcción jurídica en términos de la responsabilidad del Estado.

\section{El análisis del contexto}

La determinación de la existencia o identificación de un grupo vulnerable, en razón de la pobreza, se inicia con el análisis del contexto en el que se producen los hechos denunciados de violación de derechos humanos, en particular la situación de sometimiento a esclavitud y trata de los 85 trabajadores que se encontraban en la Hacienda en el momento de la denuncia del año 2000.

En ese análisis del contexto, la Corte IDH constató que el comercio de esclavos en Brasil ha estado históricamente ligado al trabajo forzoso y a la colonización portuguesa. A pesar de que en 1888 la esclavitud fue legalmente abolida en este país, la pobreza y la concentración de la propiedad de las tierras han sido causas estructurales que han provocado la continuación del trabajo esclavo, que incluso siguió creciendo en el siglo XX debido a técnicas de trabajo que requerían mucha mano de obra en los últimos eslabones de la economía globalizada. Todo ello aunado a una situación de impunidad proveniente de la relación establecida entre los terratenientes y los sectores del poder público. ${ }^{29}$

por pobreza y como causa de su trabajo esclavo (voto individual razonado del juez Eduardo Vio Grossi, caso Trabajadores de la Hacienda Brasil Verde vs. Brasil, párrs. 1, 3 y 4).

29 Corte IDH, caso Trabajadores de la Hacienda... cit., párrs. 111, 114 y 318. 
Esta revista forma parte del acervo de la Biblioteca Jurídica Virtual del Instituto de Investigaciones Jurídicas de la UNAM

Las víctimas de este trabajo esclavo son personas de la regiones norte y noreste de Brasil, caracterizadas por ser las más pobres y con los mayores índices de analfabetismo. Estas condiciones les convierten en víctimas fáciles de los reclutadores, quienes les prometen salarios atractivos para trabajos alejados de sus casas, que en realidad terminan siendo trabajos forzosos en condiciones de hacinamiento e insalubridad y confinados en espacios de donde es muy difícil escapar. ${ }^{30}$

Por tanto, a partir del análisis del contexto y, en particular, con base en los estudios de la Organización Internacional del Trabajo y del Ministerio de Trabajo y Empleo de Brasil, ${ }^{31}$ el Tribunal Interamericano considera probado que es la condición de pobreza extrema lo que sitúa a quienes la padecen en una posición de vulnerabilidad que hace mucho más probable que acaben trabajando en las condiciones descritas. ${ }^{32}$ Esta constatación no debería sorprendernos, dado que la relación entre pobreza y trabajo esclavo es un hecho ampliamente verificado. ${ }^{33}$

\section{El grupo vulnerable}

Las 85 víctimas concretas del caso pertenecen a ese grupo de personas identificadas con una posición económica de pobreza que caracterizó su trato discriminatorio:

La Corte constata, en el presente caso, algunas características de particular victimización compartidas por los 85 trabajadores rescatados el 15 de marzo de 2000: se encontraban en una situación de pobreza; provenían de las regiones más pobres del país, con menor desarrollo humano y perspectivas de trabajo y empleo; eran analfabetas, y tenían poca o nula escolarización. Lo anterior los colocaba en una situación que los hacía más susceptibles de ser reclutados mediante falsas promesas y engaños. Dicha situación de riesgo inmediato para un grupo determinado de personas

30 Ibidem. párrs. 112 y 113 . En concreto, la sentencia recoge la expresión de "sistema de cárcel privada” empleada por el Ministerio Público (párr. 302).

31 Ibidem, párr. 340.

32 Ibidem. párrs. 110-115.

33 Arcos Ramírez, Federico, "Globalización, pobreza y esclavitud contemporánea: una mirada cosmopolita”, en Pérez Alonso, Esteban (dir.), El derecho ante las formas de esclavitud, Valencia, Tirant lo Blanch, 2017. 
DOI: httpa//dx_doi_org/10.22201/iij_24487872e_2020.20.14474

con características idénticas y originarios de las mismas regiones del país, tiene orígenes históricos y era conocida desde, al menos, 1995, cuando el gobierno de Brasil reconoció expresamente la existencia de “trabajo esclavo” en el país. ${ }^{34}$

La cita anterior constata que el grupo de los 85 trabajadores que se encontraban en la Hacienda Brasil Verde forman parte de un grupo de personas que se caracterizan por vivir en condiciones de extrema pobreza. La "situación de riesgo inmediato" alude a la mayor vulnerabilidad en la violación de los derechos de ese "grupo determinado de personas" que, respecto al resto de la sociedad, comparten ciertas características de origen histórico. Estas inferencias nos llevan a examinar qué se está entendiendo por vulnerabilidad, grupo vulnerable, desigualdad y discriminación estructural histórica en razón de la posición económica y cuál es la relación entre estas condiciones.

El concepto de vulnerabilidad, desarrollado y expandido mayormente por el pensamiento feminista, ${ }^{35}$ hace referencia al riesgo, siempre presente, de sufrir algún tipo de daño o adversidad. Un tratamiento profundo sobre la vulnerabilidad y con notable influencia en el ámbito jurídico es el realizado por Martha A. Fineman. La teoría de la vulnerabilidad de esta pensadora estadounidense conlleva un reproche al derecho antidiscriminatorio propio del pensamiento liberal dado que se acompaña del principio de igualdad formal que es, desde su punto de vista, una perspectiva estrecha que "ignora la mayoría de los contextos, así como las diferencias en cuanto a circunstancias y habilidades" y que, por demás, "no es efectiva para combatir las fuerzas que han incrementado la desigualdad en riqueza, posición y poder".36

Fineman parte del presupuesto de que "la vulnerabilidad es inherente a la condición humana". ${ }^{37}$ Sin embargo, como también explicó esta autora, la vulnerabilidad concreta de cada persona es particular, dependiendo de su

34 Corte IDH, caso Trabajadores de la Hacienda... cit., párr. 339 (la cursiva es nuestra).

35 Véase Young, Iris Marion, "The Gendered Cycle of Vulnerability in the less Developed World”, en Satz, D. \& Reich, R. (eds.), Toward a Humanist Justice:The Political Philosophy of Susan Moller Okin, Oxford, Oxford University Press, 2009. Butler, Judith, Precarious Life:The Powers of Mourning and Violence, Londres, Verso, 2004.

36 Fineman, Martha A., "Equality, Autonomy, and the Vulnerable Subject in Law and Politics”, en Fineman, M. A. \& Grear, A. (eds.), Vulnerability. Reflections on a New Ethical Foundation for Law and Politics, Ashgate, Farnham-Burlington, 2013, p. 14.

37 Ibidem, p. 13. 
DOI: httpa//dx_doi_org/10.22201/iij_24487872e_2020.20.14474 posición y situación en la sociedad. ${ }^{38}$ Son las instituciones sociales las que deben encargarse de mediar, compensar y reducir nuestra vulnerabilidad a través de programas, instituciones y estructuras. ${ }^{39}$

Encontramos aquí una primera consecuencia que resulta de vincular la vulnerabilidad con la desigualdad porque atender a la vulnerabilidad supone encarar las desigualdades que la igualdad formal ante la ley no trata — incluso ayuda a validar - en la medida en que no cuestiona la distribución de recursos y poder. ${ }^{40}$

Una segunda consecuencia de esta vinculación entre vulnerabilidad y desigualdad la encontramos en la construcción de un grupo vulnerable. Con independencia de la existencia de una vulnerabilidad general del ser humano, es la condición de mayor vulnerabilidad de unos grupos respecto a otros lo que permite la construcción pretoriana de un trato diferenciado. ${ }^{41}$ Vulnerabilidad que supone una posición de riesgo mayor que el resto de la población respecto a la probabilidad de sufrir la violación de los derechos humanos. Si la vulnerabilidad general demanda cierta atención por parte de los poderes públicos, la vulnerabilidad agravada de estos grupos necesita una intervención más amplia del Estado. En sociedades en que existe un reconocimiento casi general de la igualdad formal (igualdad ante la ley), la noción de vulnerabilidad surge como respuesta a las debilidades del modelo liberal de la igualdad, en particular ante la carencia estrepitosa de igualdad material que se refleja en una falta de garantía de los derechos económi-

38 Maggy Barrere acierta cuando puntualiza que "una cosa es que todos seamos vulnerables y otra, distinta, que todos seamos igualmente vulnerables", un importante matiz que la "postura de Fineman no esclarece", ya que en su visión de la vulnerabilidad se mezclan las causas accidentales y las estructurales. Véase esta autora para una visión crítica de Fineman. Barrere, Ma. Ángeles (Maggy), "Martha A. Fineman y la igualdad jurídica: ¿vulnerabilidad o subordiscriminación?”, Cuadernos Electrónicos de Filosofía del Derecho, núm. 34, 2016, p. 9.

39 Fineman, Martha A., "The Vulnerable Subject: Anchoring Equality in the Human Condition”, Yale Journal of Law \& Feminism, vol. 20, núm. 1, 2008, p. 3.

40 Ibidem, p. 3.

41 En este aspecto habría un alejamiento de los presupuestos de Fineman, dado que para ella los englobados bajo la etiqueta de "grupos vulnerables" se encuentran estigmatizados y esto puede ser pernicioso porque agrupa a los individuos con base en dos o más rasgos y enmascara otras diferencias, lo que conduce a que haya agrupaciones "sobre-inclusivas y subinclusivas", Fineman, Martha A., "Equality, Autonomy, and the Vulnerable Subject in Law and Politics”, cit., p. 16. 
cos y sociales. ${ }^{42}$ Es decir, pese a la igualdad de todos ante la ley, existe un gran número de personas que debido a significativas desigualdades económicas, sociales y culturales han sido sistemáticamente excluidas del disfrute y ejercicio de sus derechos, y tienen un riesgo mayor que otros de sufrir la violación de éstos. Otorgar un mismo trato a personas que se encuentran en posiciones desiguales puede conducir a incrementar las desigualdades existentes; en consecuencia, cuando los Estados adopten medidas para mejorar las condiciones de los grupos vulnerables deben hacerlo sobre la base de una noción de igualdad material. ${ }^{43}$

\section{La discriminación (estructural histórica) en razón de la posición económica}

La posición de riesgo mayor de sufrir violaciones de derechos implica que toda vulnerabilidad supone una discriminación de facto; es decir, una desigualdad, una posición de desventaja respecto al resto de los miembros de la comunidad. ${ }^{44}$ Esa mayor vulnerabilidad, con frecuencia, tiene origen en una discriminación estructural.

Entendemos por discriminación de facto o fáctica la que existe en la realidad sin estar prescrita en la letra de la ley o en la programación estatal. La discriminación estructural, de acuerdo con la explicación del juez Ferrer

42 De acuerdo con Luis Prieto "los derechos sociales se configuran como derechos de igualdad entendida en el sentido de igualdad material o sustancial, esto es, como derechos, no a defenderse ante cualquier discriminación normativa, sino a gozar de un régimen jurídico diferenciado o desigual en atención precisamente a una desigualdad de hecho que trata de ser limitada o superada". Prieto Sanchís, Luis, "Los derechos sociales y el principio de igualdad sustantiva”, Revista del Centro de Estudios Constitucionales, núm. 22, 1995, p. 16. En el mismo sentido se pronuncia María José Añón cuando señala que los derechos sociales "no presumen que los seres humanos son seres autónomos, libres e iguales, sino que deben serlo y para ello son necesarios contextos institucionales adecuados que lo hagan posible”. Añón, María José, "Derechos sociales: inconsistencias de una visión compartimentada", en Varios autores, Teoría de la justicia y derechos fundamentales. Estudios en homenaje al profesor Gregorio Peces-Barba, Madrid, Dykinson, 2008, p. 39.

43 Parra, Oscar, "Derechos humanos y pobreza en el Sistema Interamericano", Revista del Instituto Interamericano de Derechos Humanos, núm. 56, julio-diciembre de 2012, p. 294.

44 Entendemos aquí la igualdad y la no discriminación como los aspectos positivo y negativo, respectivamente, de un mismo fenómeno. Bayebsky, Anne F., "El principio de igualdad y no discriminación en el derecho internacional”, Human Rights Law Journal, vol. 11, núms. $1-2,1990$, nota 1 . 
Mac-Gregor en su voto razonado, hace alusión a la existencia de grupos cuyos miembros tienen características inmodificables por su propia voluntad; padecen una exclusión sistemática que les ha impedido acceder a condiciones básicas de desarrollo humano; se concentran en una zona geográfica determinada y, con independencia de la intención de la norma, sufren de hecho una discriminación indirecta por la acción del Estado. ${ }^{45}$

La discriminación indirecta se encuentra "relacionada con el impacto desproporcionado de normas, acciones, políticas u otras medidas que, aun cuando sean o parezcan ser neutrales en su formulación, o tengan un alcance general y no diferenciado, producen efectos negativos para ciertos grupos vulnerables". ${ }^{46}$ La discriminación indirecta tiene que ver con una forma determinada de entender el principio de igualdad y para evitarla se requiere una visión de la igualdad que no permanezca ciega ante normas en apariencia neutras y universales, y permita un trato diferencial, sin que necesariamente tenga que interpretarse como preferencial. ${ }^{47}$ También supone introducir la idea de que no es necesario que exista intencionalidad para considerar que se está produciendo discriminación. ${ }^{48}$

En la sentencia Hacienda Brasil Verde se aprecian diferentes aspectos discriminatorios que reflejan características propias de condiciones de discriminación estructural. En primer lugar, se atestigua un trato discriminatorio directo, proveniente del propio Estado como parte de la violación del derecho a la protección judicial. En el fallo del Tribunal Interamericano se hace constar que las autoridades ignoraron la "extrema gravedad" de los hechos y, por consiguiente, no actuaron "con la debida diligencia necesaria para garantizar los derechos de las víctimas”. La falta de actuación y de sanción responde a las condiciones "a las que continuamente eran sometidas personas con determinadas características en los estados más pobres de Brasil”. ${ }^{49}$

45 En 2009 la Corte IDH llevó a cabo un relevante desarrollo jurisprudencial sobre el concepto de discriminación estructural en el emblemático caso González y otras ("Campo Algodonero") vs. México, excepción, preliminar, fondo, reparaciones y costas. Sentencia de 16 de noviembre de 2009, Serie C, núm. 205.

46 Parra, Oscar, op. cit., p. 299.

47 Véase, Corte IDH, caso Nadege Dorzema y otros vs. República Dominicana. Fondo, reparaciones y costas, sentencia de 24 de octubre de 2012, serie C, núm. 251, párrs. 108 y 235.

48 Voto razonado del juez Eduardo Ferrer Mac-Gregor, caso Trabajadores de la Hacienda Brasil VerdeVs. Brasil, párr. 86.

49 Corte IDH, Caso Trabajadores de la Hacienda..., cit. párr. 418. 
Esta falta de debida diligencia y de castigo por hechos que pueden calificarse de condiciones de esclavitud responde a prejuicios o concepciones preconcebidas de lo que es considerado como circunstancias normales de trabajo. Esta actitud dio como resultado una actuación discriminatoria que entorpeció la posibilidad de sancionar a los responsables.

En segundo lugar, el apartado en que se relaciona la pertenencia de los 85 trabajadores rescatados a un grupo de personas que históricamente han vivido en una situación de pobreza se titula "Discriminación estructural". ${ }^{50}$ Aquí, los jueces identifican a las víctimas del caso con un grupo social que durante décadas ha sufrido una discriminación fáctica que los sitúa en un contexto de vulnerabilidad que es calificada de estructural histórica. No es una situación de "meros tratos arbitrarios", sino de un "diseño del sistema social que coloca a determinados grupos en una condición desventajosa". ${ }^{51}$

Esto significa que, en este fallo, por un lado, vulnerabilidad y discriminación estructural se encuentran fuertemente entrelazadas ${ }^{52} \mathrm{y}$, por el otro, que para abordar la pobreza se introduce la noción de grupo vulnerable que sufre discriminación estructural, una discriminación que no puede ser resuelta con la igualdad formal.

La identificación de un grupo vulnerable ha estado frecuentemente asociada a la identificación de una discriminación estructural de ese grupo y, algunas veces, ha llegado a suponer la responsabilidad del Estado por violación del principio de igualdad y no discriminación, tanto del artículo 1.1.

50 Ibidem, apartado B.12 del capítulo VIII-1.

51 Parra, Oscar, op. cit., p. 284.

52 En su jurisprudencia, la Corte IDH ha aludido a la relación entre vulnerabilidad y discriminación desde múltiples perspectivas. En ocasiones, es el propio Estado el que ha causado la vulnerabilidad a través de políticas directa o indirectamente discriminatorias. En otros casos, se ha considerado la existencia de discriminación sin hacer explícita la vulnerabilidad de las víctimas de la misma; o la identificación explícita de un grupo vulnerable no ha estado ligada a considerar probado el trato discriminatorio. Respectivamente: Corte IDH, caso de Las niñas Yean y Bosico vs. República Dominicana. Sentencia del 8 de septiembre de 2005, Serie C, núm. 130, párrs. 172, 173, 205, 224 y 227. Corte IDH, caso Perozo y otros vs. Venezuela, Excepciones preliminares, fondo, reparaciones y costas, Sentencia de 28 de enero de 2009, Serie C, núm. 195, párr. 360. Corte IDH, caso Atala Riffo y niñas vs. Chile, Fondo, reparaciones y costas, Sentencia de 24 de febrero de 2012, Serie C, núm. 239. Corte IDH, caso de los Pueblos Indígenas Kuna de Madungandí y Emberá de Bayano y sus miembros vs. Panamá, Excepciones preliminares, fondo, reparaciones y costas, Sentencia del 14 de octubre de 2014, Serie C, núm. 284, párrs. 164, 167, 149, y punto resolutivo 8 . 
de la $\mathrm{CADH},{ }^{53}$ como de la igualdad ante la ley interna del artículo 24 del mismo instrumento. ${ }^{54}$ De esto se sigue que la vulnerabilidad va asociada a discriminación estructural cuando el riesgo proviene de una desigualdad material enraizada en la sociedad y en el tiempo.

Como corolario de lo anterior, podemos concluir que en la sentencia del caso Hacienda BrasilVerde se considera que los 85 trabajadores rescatados en el año 2000 forman parte de un grupo humano mayor que se encuentra determinado espacialmente (regiones norte y noreste de Brasil) y que se caracteriza por rasgos concretos (pobreza, menor desarrollo humano y perspectivas de empleo, analfabetismo, poca o nula escolarización), que se sintetizan en la condición de pobre, vulnerable y víctima de discriminación estructural histórica. Se identifica así un nuevo grupo vulnerable: el de los pobres de estas regiones de Brasil.

\section{La responsabilidad estatal frente a la vulnerabilidad y la discriminación estructural}

De acuerdo con la sentencia Hacienda Brasil Verde, los Estados no sólo deben abstenerse de crear situaciones de discriminación de iure o de facto; tam-

53 En la mencionada sentencia conocida como "Campo algodonero", el Tribunal Interamericano consideró "que la violencia contra la mujer constituyó una forma de discriminación y declara que el Estado violó el deber de no discriminación contenido en el artículo 1.1 de la Convención, en relación con el deber de garantía de los derechos consagrados en los artículos 4.1, 5.1, 5.2 y 7.1 de la Convención Americana" (párr. 402). Sin embargo, el concepto de discriminación estructural se utilizó, especialmente, como contexto para fijar las medidas de reparación como medidas de reparación transformadora que tuvieran un efecto no sólo restitutivo, sino también correctivo, sin intención de responsabilizar al Estado por ello. Con relación a ello, el fallo señala: "Los tres homicidios por razones de género del presente caso ocurrieron en un contexto de discriminación y violencia contra la mujer. No corresponde a la Corte atribuir responsabilidad al Estado sólo por el contexto, pero no puede dejar de advertir la gran importancia que el esclarecimiento de la antedicha situación significa para las medidas generales de prevención que debería adoptar el Estado a fin de asegurar el goce de los derechos humanos de las mujeres y niñas en México e invita al Estado a considerarlo” (párr. 463).

54 La Corte ha precisado que cuando se alega discriminación respecto a un derecho recogido en la propia CADH, debe analizarse bajo el artículo 1.1 y el derecho sustantivo en cuestión. Si por el contrario la alegada discriminación se refiere a una protección desigual de la ley interna, el hecho debe examinarse bajo el artículo 24 de la misma. Corte IDH. Propuesta de modificación a la Constitución Política de Costa Rica relacionada con la naturalización. Opinión Consultiva OC-4/84 de 19 de enero de 1984, serie A, núm. 4, párr. 199. 
bién están obligados a adoptar medidas positivas para revertir las situaciones de discriminación en las que viven determinados grupos de personas. Asimismo, la Corte IDH ha dictaminado que toda persona que se encuentre en una situación de vulnerabilidad es titular de una protección especial y, en consecuencia, no es suficiente con que los Estados se abstengan de violar los derechos, sino que deben adoptar medidas positivas diseñadas en función de las necesidades que requiere el sujeto para estar protegido. En el caso que nos ocupa estas necesidades están determinadas por la condición y situación específica de pobreza y marginación de los trabajadores de la Hacienda Brasil Verde. ${ }^{55}$

Hemos visto que la vulnerabilidad supone una discriminación fáctica, dado que, por definición, implica un mayor riesgo de sufrir violación de los derechos humanos. Ahora bien, para que haya una discriminación que transgreda el principio de igualdad y no discriminación que obliga internacionalmente al Estado, ${ }^{56}$ es necesario que éste genere directamente esa discriminación creando o agravando la vulnerabilidad $;{ }^{57}$ o que, conociendo esa situación de vulnerabilidad, no lleve a cabo las medidas positivas necesarias para evitar la violación de los derechos. Cuando la Corte afirma que "de la prueba aportada al expediente se advierte la existencia de una situación basada en la posición económica de las víctimas rescatadas el 15 de marzo de 2000 que caracterizó un trato discriminatorio", ${ }^{58}$ está aludiendo a la discriminación que sufrieron por parte del Estado y que acabará implicando su responsabilidad.

La condición de vulnerabilidad hace que no sea suficiente que el Estado se abstenga de violar los derechos para cumplir con sus obligaciones de respeto y garantía, como son determinadas en el artículo 1.1 de la CADH. Por

55 Corte IDH, caso Trabajadores de la Hacienda..., cit. párrs. 336 y 337.

56 Hay que recordar que la Corte IDH ha considerado que "en la actual etapa del derecho internacional, el principio fundamental de igualdad y no discriminación ha ingresado en el dominio del jus cogens" (Corte IDH, Condición jurídica y derechos de los migrantes indocumentados, Opinión Consultiva OC-18/03 del 17 de septiembre de 2003, Serie A, núm. 18, párr. 101. Reproducido en el párr. 416 de la sentencia que aquí es objeto de estudio).

57 Véase Corte IDH, caso Perozo y otros vs.Venezuela, Excepciones preliminares, fondo, reparaciones y costas, Sentencia de 28 de enero de 2009, Serie C, núm. 195, párr. 360; y Corte IDH, caso de Las niñas Yean y Bosico vs. República Dominicana, Sentencia de 8 de septiembre de 2005, Serie C, núm. 130, párrs. 172, 173, 205, 224 y 227.

58 Corte IDH, caso Trabajadores de la Hacienda..., cit., párr. 340. 

el contrario, se vuelve imperativa la adopción de "medidas positivas, determinables en función de las particulares necesidades de protección del sujeto de derecho, ya sea por su condición personal o por la situación específica en que se encuentre". ${ }^{59}$ De modo que aun cuando la violación directa de los derechos provenga de comportamientos de otros sujetos distintos del Estado, éste incurre en responsabilidad. En la medida en que toda persona que se encuentre en una situación de vulnerabilidad es titular de una protección especial, el Estado “incurre en responsabilidad internacional en aquellos casos en que, habiendo discriminación estructural, no adopta medidas específicas respecto a la situación particular de victimización en que se concreta la vulnerabilidad sobre un círculo de personas individualizadas". ${ }^{60}$

En 1995 Brasil reconoció la existencia de trabajo esclavo y comenzó a tomar medidas para combatirlo. No obstante, pese a que conocía el caso concreto de la Hacienda Brasil Verde por una serie de inspecciones realizadas con anterioridad al reconocimiento por parte del Estado de la competencia de la Corte, el Estado no adoptó las medidas a las que estaba obligado para evitar que un grupo de personas en situación de pobreza extrema fueran víctimas de la esclavitud. Además, tras la denuncia del año 2000, tampoco investigó, procesó ni sancionó estos delitos, como razonablemente era de esperarse dada la gravedad de los hechos. ${ }^{61}$

Para determinar la responsabilidad estatal, la Corte volvió a recordar (en particular, respecto a los derechos del artículo 6o. de la CADH) que el Estado tiene el deber de prevenir e investigar las posibles violaciones a los derechos y de adoptar medidas integrales con la debida diligencia. El objetivo es claro, no sólo se trata de que exista un adecuado marco jurídico de protección, sino también una aplicación efectiva del mismo y unas políticas

59 Ibidem, párr. 316. En el mismo sentido: Corte IDH, caso Artavia Murillo (Fecundación in vitro) vs. Costa Rica. Excepciones preliminares, fondo, reparaciones y costas, sentencia de noviembre 2012, serie C, núm. 257, párr. 292; Corte IDH, caso Masacre de Mapiripán vs. Colombia. Sentencia de 15 de septiembre de 2015, serie C, núm. 134, párrs. 111, 113; Corte IDH, caso Ximenes Lopes vs. Brasil. Sentencia de 4 de julio de 2006, serie C, núm. 139, párr.103; Corte IDH, caso Pueblo Indígena Kichwa de SarayakuVs. Ecuador. Fondo y reparaciones, sentencia de 27 de junio de 2012, serie C, núm. 245, párr. 244; Corte IDH, caso Furlán y familia vs. Argentina. Excepciones preliminares, fondo, reparaciones y costas, sentencia del 31 de agosto de 2012, serie C, núm. 246, párr. 134.

60 Corte IDH, caso Trabajadores de la Hacienda..., cit., párr. 338.

61 Ibidem, párrs. 116 y 325-328. 

públicas que eviten los factores de riesgo y fortalezcan las instituciones de manera que pueda proporcionarse una respuesta efectiva. ${ }^{62}$

El deber de prevención no supone que el Estado sea responsable de cualquier violación de derechos humanos entre particulares cometida en su territorio, pues su deber de actuar se encuentra condicionado al "conocimiento de una situación de riesgo real e inmediato ${ }^{63}$ para un individuo o grupo de individuos determinado y las posibilidades razonables de prevenir o evitar ese riesgo". ${ }^{64}$

En el caso Hacienda BrasilVerde se constataron una serie de fallas y negligencias por parte del Estado en dos niveles. Un nivel más general y lejano lo constituye el contexto del caso objeto de la sentencia, configurado por las denuncias que desde 1988 se fueron produciendo periódicamente sobre la existencia de trabajo esclavo en el Estado de Pará y, específicamente, en la Hacienda Brasil Verde. Estas denuncias supusieron la apertura de procedimientos penales y laborales, pero no se logró cambiar la situación de las personas que acudieron a la Corte. El segundo nivel, más inmediato a la realidad de los 85 trabajadores del caso, es el generado por la denuncia de los adolescentes que lograron escapar en marzo de 2000 y que pusieron una denuncia. El Estado no respondió como debía y no desplegó todo su aparato coercitivo para hacer frente a las graves violaciones de derechos humanos que de nuevo llegaban a su conocimiento. Al no hacerlo, violó su deber de impedir la existencia de esclavitud en su territorio. ${ }^{65}$

Lo relevante del caso es que el principio de igualdad y no discriminación se ve vulnerado debido a la "categoría sospechosa" o "rubro prohibido de discriminación” de la posición económica de la persona, que la Corte identificó con la pobreza o pobreza extrema, destacando que, a diferencia

62 Ibidem, párr. 320.

63 La Corte IDH consideró la existencia de esa "situación de riesgo inmediato" en la caracterización de las víctimas del caso.

64 Corte IDH, caso Trabajadores de la Hacienda..., cit., párr. 323.

65 "En esa oportunidad, al recibir la denuncia de los adolescentes sobre los delitos ocurriendo en la referida hacienda, la condición de niño de Antônio Francisco da Silva y la gravedad de los hechos denunciados, la policía simplemente informó que no podría atenderlos por ser carnaval y les orientó a regresar dentro de dos días. Dicha actitud estuvo en franca contradicción con la obligación de debida diligencia, sobre todo cuando los hechos denunciados se referían a un delito tan grave como la esclavitud”, ibidem, párr. 327. 
de otros tratados de derechos humanos, es una de las causales de discriminación prohibida por el artículo 1.1. de la CADH.

Si bien el listado de las categorías sospechosas que acompañan la redacción del principio de igualdad y no discriminación suele ser un numerus apertus,${ }^{66}$ tiene relevancia por varias razones. En primer lugar, porque identifica grupos sociales susceptibles de sufrir discriminaciones injustificadas que tienen el efecto de excluirlos del goce o el ejercicio de derechos; en segundo lugar, porque las categorías recogidas en el listado implican la necesidad de un control estricto del empleo de esos factores como base de distinciones de jure o de facto (que supondría la inversión de la carga de la prueba, una presunción de invalidez de la distinción y la necesidad de justificación estricta de la medida que se juzga). ${ }^{67}$

\section{EXAMEN CRÍTICO Y APORTACIONES}

El profesor argentino Roberto Saba, quien ha estudiado en profundidad el tema de la igualdad y la desigualdad estructural, afirmó que

... si fuera posible establecer un vínculo entre un tipo particular de pobreza y la afectación consiguiente del derecho a ser tratado igual, entonces estaríamos ante un argumento capaz de justificar la responsabilidad constitucional o de derecho internacional del Estado de desmantelar las causas que llevan a esa afectación. ${ }^{68}$

La Corte parece haber logrado esa conexión con la sentencia del caso Hacienda BrasilVerde a través de la construcción jurídica siguiente: partiendo del análisis del contexto, identifica un grupo vulnerable por pobreza y su discriminación estructural histórica; determina la pertenencia a ese grupo de las víctimas del caso, así como su situación de riesgo cierto e inmediato.

66 El artículo 1.1. de la CADH termina: "o cualquier otra condición social”.

67 Courtis, Christian, "Dimensiones conceptuales de la protección legal contra la discriminación”, Revista Derecho del Estado, núm. 24, julio de 2010, pp. 115 y 122.

68 Saba, Roberto, Pobreza, derechos y desigualdad estructural, México, Suprema Corte de Justicia de la Nación, Tribunal Electoral del Poder Judicial de la Federación, Instituto Electoral del Distrito Federal, 2012, p. 45. 

Ello genera la obligación del Estado de protección activa; su omisión o acción ineficaz le supone incurrir en responsabilidad.

\section{El papel jugado por el análisis del contexto}

El análisis del contexto es fundamental y probablemente imprescindible para abordar un enfoque grupal. De acuerdo con las palabras del juez interamericano Humberto Sierra Porto, en determinadas circunstancias la consideración del contexto es imprescindible por dos motivos. Por un lado, sirve para llenar los vacíos probatorios y precisar el alcance y el contenido de la denuncia; para complementar los hechos específicos del caso concreto, y para entenderlos y valorarlos una vez ubicados dentro del contexto; por otro lado, también es de utilidad para que una vez ubicado el caso en un específico contexto puedan determinarse presunciones de responsabilidad del Estado. ${ }^{69}$

En principio, la Corte IDH fue concebida para conocer de violaciones individuales de derechos humanos. Sin embargo, en la medida en que se ha enfrentado a fenómenos que eran parte de violaciones sistemáticas de derechos se ha ido ocupando de la discriminación estructural de determinados grupos sociales. Cuando la vulnerabilidad está ligada a discriminación estructural, estamos hablando de grupos vulnerables, no de individuos, dado que "esa vulnerabilidad va asociada a una condición determinada que permite identificar al individuo como integrante de un determinado colectivo que, como regla general, está en condiciones de clara desigualdad material con respecto al colectivo mayoritario". ${ }^{70} \mathrm{El}$ análisis del contexto provee el conocimiento de las condiciones de ese grupo — vulnerable y discriminado de manera estructural — al que pertenecen las víctimas concretas del caso.

En la sentencia Hacienda Brasil Verde, la identificación de un grupo vulnerable de pobres comienza con el análisis del contexto. Si bien el caso que llega a la Corte IDH es de personas individualmente consideradas, su apreciación como miembros de ese grupo es fundamental. Porque el análisis del

69 Palabras pronunciadas en la conferencia "La utilización del «contexto» en la jurisprudencia Interamericana”, celebrada el 15 de marzo de 2016 en el Centro de Estudios Políticos y Constitucionales, Madrid, España.

70 Felipe Beltrão, Jane et al. "Prólogo" a Derechos humanos de los grupos vulnerables, Barcelona, Red de Derechos Humanos y Educación Superior, 2014, p. 14. 
DOI: httpa//dx_doi_org/10.22201/iij_24487872e_2020.20.14474 contexto no sólo sirve para probar la existencia del grupo, sino también su desventaja o el riesgo especial de dicho grupo, el carácter estructural de esa discriminación y, por tanto, su configuración como grupo vulnerable.

De este modo, el análisis del contexto sirve de elemento de prueba respecto a la situación de especial vulnerabilidad de los trabajadores concretos del caso y de la violación de sus derechos humanos. Pero también como prueba de su pertenencia a un grupo de personas que viven en esa situación de vulnerabilidad desde hace mucho tiempo, lo que permitió enunciar la existencia de una discriminación estructural histórica.

En el caso concreto que nos ocupa, el análisis del contexto muestra como causas subyacentes circunstancias históricas, políticas y sociales de exclusión en el goce de los derechos de determinado grupo de población caracterizado, principalmente, por su pobreza. Causas subyacentes que se ven reforzadas por macro fuerzas como la globalización. ${ }^{71} \mathrm{Al}$ mismo tiempo, se constata el carácter estructural de esos grupos y de su exclusión, puesto que no logran cambiar sus circunstancias a lo largo del tiempo, lo cual facilita o está ligado a la impunidad de las violaciones de sus derechos. ${ }^{72}$ Esto conduce a que "se normalice" su no acceso al desarrollo de sus capacidades y a la satisfacción de sus necesidades. Ante esta situación, la acción del Estado

71 "En atención al elevado número de víctimas de esclavitud, trata y servidumbre que continúan siendo liberadas por parte de las autoridades brasileñas y al cambio de perspectiva de esos fenómenos y su ocurrencia «en los últimos eslabones de las cadenas de suministro de una economía globalizada», es importante que el Estado adopte medidas para desalentar la demanda que alimenta la explotación del trabajo, tanto a través de trabajo forzoso como de servidumbre y esclavitud" (Corte IDH, Caso Trabajadores de la Hacienda Brasil Verde vs. Brasil, párr. 318). Sobre causas subyacentes véase: Estupiñán-Silva, Rosmerlin, "La vulnerabilidad en la jurisprudencia de la Corte Interamericana de Derechos Humanos: esbozo de una tipología”, en Laurence Burgorgue-Larsen et al. (coords.), Derechos humanos y políticas públicas, Barcelona, Red de Derechos Humanos y Educación Superior, 2014.

72 A este respecto y de cara a la responsabilidad estatal, el análisis del contexto se vería fortalecido si se analiza la relación estructural, por un lado, entre pobreza, trabajo esclavo y colonialismo. Investigaciones, profundamente rigurosas y documentadas, como las de Jacob Gorender pueden ser de gran ayuda ( $O$ escravismo colonial, Sâo Paulo, Editora Âtica, 1978). Y, por otro lado, la relación estructural entre racismo, pobreza y esclavismo. Sobre ello, los trabajos del reconocido intelectual Abdias Nascimento centrados en el racismo, la discriminación y la condición post-abolicionista son una referencia obligada para comprender el trabajo esclavo contemporáneo ( $O$ genocídio do negro brasileiro, Rio de Janeiro, Paz et Terra, 1978). Mencionamos estos trabajos, pero no profundizamos en ellos porque, como ya hemos mencionado, nuestro objetivo está centrado en la pobreza y no en el trabajo esclavo. 
está ausente o es insuficiente, mostrando un contexto de negligencia institucional, puesto que la actuación de los poderes públicos es partícipe de esa "normalización" de la discriminación. Esta es la situación que la propia sentencia describe respecto al derecho de acceso a la justicia.

Otra consecuencia significativa de la utilización del contexto es, siguiendo nuevamente a Sierra Porto, la dinamización del diálogo y la intercomunicación entre los distintos órganos internacionales en materia de derechos humanos, tanto regionales como universales. Ello es así, porque permite que sus trabajos, normalmente propios del soft law, van desdibujando su carácter meramente declarativo o programático y, con base en elementos probatorios de casos concretos, coadyuvan a una mejor eficacia jurídica. El contexto, de acuerdo con las palabras de este juez colombiano, es un instrumento para hacer obligatorios, de alguna manera, los informes de los órganos internacionales que velan por los derechos humanos. ${ }^{73}$ Siguiendo esta línea argumental y tomando en cuenta que, en septiembre de 2017, tan sólo unos meses después de fallada la sentencia Hacienda BrasilVerde, la CIDH dio a conocer su "Informe sobre pobreza y derechos humanos en las Américas", no cabe duda de que estamos ante uno de esos escenarios en el que soft law y hard law se interrelacionan, en este caso para configurar nuevos estándares de futuro en materia de lucha contra la pobreza.

2. Consecuencias de la identificación de un grupo vulnerable de pobres y la consideración de la discriminación en razón de la posición económica

La identificación de un grupo vulnerable de pobres es clave, como hemos mostrado, para acabar determinando la responsabilidad estatal por las

73 Sobre ello, llama la atención que en la Sentencia Brasil Verde no se hiciera referencia al caso de José Pereira relacionado con trabajo esclavo. Fue el primer caso en llegar a la CIDH, en diciembre de 1994, mediante un litigio realizado por el Centro por la Justicia y el Derecho Internacional (CEJIL), Americas Watch y la Comisao Pastoral da Terra y que, tras la firma de solución amistosa en septiembre de 2003, se responsabilizó internacionalmente al Estado. Tras la denuncia, si bien nadie ha sido condenado, el Estado de Brasil adoptó una serie de medidas como son la creación del Plan Nacional para la Erradicación del Trabajo Esclavo y la Comisión Nacional de Erradicación del Trabajo Esclavo. También se crea la "lista sucia" de trabajo esclavo que es considerada una de las principales herramientas en la lucha contra ese delito y es tomada como referencia por las Naciones Unidas. Sin embargo, dicha lista fue recientemente suspendida. 
violaciones de derechos humanos de los miembros de este grupo cometidas por terceros. Hemos observado también que la discriminación estructural y, por supuesto, histórica, es predicada de un grupo social identificado, a través del análisis del contexto. Conviene detenernos en el concepto de grupo antes de atender las consecuencias del nuevo grupo considerado vulnerable sólo por pobreza.

Owen Fiss, con cuyo punto de vista suele haber una cierta aquiescencia, señala que para poder hablar de grupo se deben cumplir las características siguientes: el grupo ha de constituir una entidad de modo que tenga una existencia distinta de la de sus miembros, de modo que es viable referirse al grupo sin necesidad de aludir a los miembros que lo integran; existe una interdependencia entre la identidad y bienestar del grupo y la identidad y el bienestar de sus miembros; los miembros del grupo se autoidentifican como pertenecientes a él, y su estatus resulta en parte determinado por el estatus del grupo. ${ }^{74}$

Con independencia de la dificultad de determinar en la práctica la existencia de un grupo con esas características, la Corte IDH en este caso parece encontrar un grupo en los pobres que durante décadas han habitado las regiones norte y noreste de Brasil con las características ya descritas. ${ }^{75}$

La aproximación que la Corte IDH hace del grupo de los pobres es muy cercana a la descrita por Saba (quien parte de la definición de grupo de Fiss) al establecer los elementos definitorios del grupo sometido, caracterizado por pobreza estructural: la intergeneracionalidad de la pobreza, la dificultad de acceder a servicios públicos básicos como la educación, la identidad de los pobres como grupo, la concentración territorial, la vinculación del estatus social del individuo al del grupo, la interrelación entre los miembros del grupo, la perpetuación de la situación en el tiempo y su vínculo con otros rasgos ligados al sometimiento (indígenas, mujeres, afrodescendientes...). ${ }^{76}$

74 Fiss, Owen, "Grupos y la cláusula de la Igual Protección”, en Gargarella, Roberto (comp.), Derecho y grupos desaventajados, Barcelona, Gedisa, 1999, pp. 138 y 139.

75 No hay consenso en la apreciación de que los pobres puedan constituir un grupo social. Una voz autorizada como la de Courtis, por ejemplo, cuestiona que "los pobres" puedan considerarse grupo, estimándolos más cerca de la noción de "agrupado", que es fruto de una mera clasificación intelectual o legal, sin reflejar una experiencia colectiva de carácter social. Courtis, Christian, op. cit., pp. 114 y 115.

76 Saba, Roberto, op. cit. pp. 49-52. 
Se trataría, por tanto, de uno de esos grupos desventajados o especialmente vulnerables identificados con grupos que, históricamente y de manera estructural han padecido dominación, explotación, exclusión, etcétera, de modo que la privación o el daño padecidos por sus miembros "no luce fortuito o casual, pudiéndose anticipar casi siempre mirando el desempeño normal de las prácticas formales e informales en una sociedad". ${ }^{77}$

Por otro lado, hemos considerado que la vulnerabilidad hace referencia al mayor riesgo, siempre presente, de padecer algún tipo de daño o adversidad. En el contexto que nos ocupa supone la violación de los derechos humanos de personas o grupo de personas debido a su condición personal o su situación específica. Esta dicotomía es establecida por la jurisprudencia de la Corte cuando habla de los deberes especiales de garantía que supone para el Estado el conocimiento de estas situaciones de vulnerabilidad, en tanto que las correspondientes medidas positivas serán "determinables en función de las particulares necesidades de protección del sujeto de derecho, ya sea por su condición personal o por la situación específica en que se encuentre, como la extrema pobreza o la marginación". ${ }^{78}$

La lectura de la jurisprudencia de la Corte IDH muestra que esta distinción es adoptada para precisar las situaciones de vulnerabilidad. Así, son personas vulnerables por su condición personal, los miembros de los pueblos indígenas, los niños y jóvenes, las mujeres, los discapacitados, los que tienen una orientación sexual minoritaria, los portadores delVIH. Mientras que se consideran vulnerables por su situación específica los migrantes, especialmente los indocumentados; los que sufren detención ilegal; los privados de libertad, especialmente si son extranjeros o sufren incomunicación; los apátridas y, de acuerdo con la sentencia Hacienda Brasil Verde, ahora también los pobres.

El valor de la distinción radica en que la vulnerabilidad por condición personal remite a unas características que no se pueden o no se deben remover. Son las diferencias fruto de las diversidades de nuestras identidades personales que, como explica el profesor Ferrajoli, hay que tutelar. ${ }^{79}$

77 Sahuí, Alejandro, "Derechos humanos y grupos desaventajados en el marco del Estado constitucional”, Perspectivas Internacionales, vol. 11, núm. 1, febrero-julio de 2015, p. 151.

78 Corte IDH, Caso Trabajadores de la Hacienda..., cit. párr. 337 (la cursiva es nuestra).

79 Ferrajoli, Luigi, "La igualdad y sus garantías", en Ruiz, Alfonso y Macía, Andrea (eds.), Desafíos de la igualdad, desafíos a la igualdad, Madrid, UAM y BOE, 2009, pp. 311 y 312. 
Mientras que la vulnerabilidad por situación específica está ligada a circunstancias absolutamente cambiables, corregibles. Es cierto que, muchas veces, elementos de vulnerabilidad de uno u otro tipo se unen y combinan, generando una situación más compleja y de mayor riesgo. Para comprender los alcances reales de riesgo que conlleva la vulnerabilidad hay que observar el contexto concreto. De hecho, la pobreza suele estar presente en casi todas las situaciones de vulnerabilidad, lo cual constituye un reclamo más para exigir respuestas jurídicas y políticas que encaren desde los derechos humanos las situaciones de pobreza.

La constitución de un grupo vulnerable sólo por la condición de pobreza supone la identificación de una vulnerabilidad exclusivamente ligada a una situación específica. ¿Qué tipo de fragilidad caracteriza al grupo vulnerable de los pobres? Parece tratarse de un caso de fragilidad social, ${ }^{80}$ en el que es la situación específica de los miembros del grupo y no su condición personal, lo que determina su vulnerabilidad. Se trata, por tanto, de un problema que es posible afrontar con las políticas públicas adecuadas. No hay factores intrínsecos a los miembros del grupo que determinen su vulnerabilidad; todo lo que les hace vulnerables puede ser y debe ser combatido por la acción del Estado.

La sentencia muestra que la identificación de ese grupo de pobres caracterizado por una desigualdad estructural afecta al derecho a la igualdad y el Estado debe hacerse cargo de desmantelar las condiciones que generan esta situación. Es imprescindible, por tanto, continuar con la superación de un concepto de igualdad formal y adoptar, como lo ha ido haciendo la jurisprudencia interamericana, "un concepto de igualdad material en el que se visibilicen las situaciones de discriminación estructural". ${ }^{81}$

Este esfuerzo en la lucha contra la pobreza podría, además, liberar a otros grupos de gran parte de su carga de vulnerabilidad dado que la pobreza suele ser la situación específica que acompaña, como agravante o de manera combinada, la vulnerabilidad por la condición personal (de mujeres, niños, minorías étnicas, etcétera). Ahora bien, conviene dejar claro que

80 Estupiñán-Silva, Rosmerlin, op. cit., p. 212.

81 Chinchilla, Fernando et al., "Pobreza y derechos humanos: hacia la definición de parámetros conceptuales desde la doctrina y acciones del sistema interamericano”, en Autores varios ¿Quién responde por los derechos humanos de las poblaciones más pobres en América Latina y El Caribe? Democracia vs. Desigualdad (2007-2011), San José, Instituto Interamericano de Derechos Humanos, 2012, p. 35. 

el "el objeto de la acción de los Estados no ha de ser el de tratar a los pobres como un objeto de medidas de ayuda, de socorro y de control, sino como sujetos de derecho". ${ }^{82}$

En definitiva, la creación de este grupo vulnerable que sufre discriminación estructural en razón de la posición económica es un elemento clave en la vinculación jurídica entre pobreza y derechos humanos y, por tanto, de la lucha legal contra la pobreza. Estamos ante un nuevo acicate para hacer más eficaz la protección judicial.

3. La pobreza como causa de las violaciones de derechos humanos y nuevos estándares para su juridificación

La pobreza es, al mismo tiempo, causa y consecuencia de graves y numerosas violaciones a los derechos humanos. ${ }^{83}$ Sin embargo, desde la perspectiva del derecho internacional de los derechos humanos, no toda privación constituye una violación de derechos humanos. Los intentos por relacionar ambos ámbitos conceptuales han sido múltiples, pero sin lograr un criterio unificado y desde terrenos de soft law. ${ }^{84}$

En la sentencia Hacienda BrasilVerde, la Corte IDH ha considerado la pobreza como causa de la violación de los derechos humanos que sufren los trabajadores del caso. Dicha causalidad tiene consecuencias en la determi-

82 Nikken, Pedro, "Los sistemas internacionales de protección de los derechos humanos: la perspectiva del acceso a la justicia y la pobreza”, Revista del Instituto Interamericano de Derechos Humanos, núm. 48, julio-diciembre de 2008, p. 103.

83 Véase Cuéllar M., Roberto, "Los derechos humanos de los más pobres: una ruta por construir en el sistema interamericano", y Dulitzky, Ariel E., "Pobreza y derechos humanos en el sistema interamericano. Algunas aproximaciones preliminares", ambos trabajos en Revista del Instituto Interamericano de Derechos Humanos, núm. 48, julio-diciembre de 2008.

84 En el marco de las Naciones Unidas se ha considerado que la pobreza constituye una negación de todos los derechos humanos (Programa de las Naciones Unidas para el Desarrollo), al menos cuando los derechos humanos involucrados afectan a las capacidades básicas (Alto Comisionado para los Derechos Humanos); se ha concebido el derecho a no ser pobre como un derecho humano en sí mismo (UNESCO); y también se ha considerado la pobreza como una violación del derecho al desarrollo (Programa de Naciones Unidas sobre el Derecho al Desarrollo). Doz Costa, Fernanda, "Pobreza y derechos humanos: desde la retórica a las obligaciones legales. Una descripción crítica de los marcos conceptuales”, Sur. Revista Internacional de Derechos Humanos, núm. 9, 2008. 
Esta revista forma parte del acervo de la Biblioteca Jurídica Virtual del Instituto de Investigaciones Jurídicas de la UNAM

nación de la responsabilidad internacional estatal, que se vehiculiza a través del concepto de grupo vulnerable y la consideración de su discriminación estructural que como violación del principio de igualdad y no discriminación por posición económica.

El fenómeno de la pobreza es complejo, y la vinculación entre ésta y la violación de derechos humanos no puede generalizarse. No toda privación específica que pueda ser caracterizada como pobreza es necesariamente una violación de derechos humanos. ${ }^{85} \mathrm{Ni}$ todos los pobres (con independencia del enfoque de pobreza que utilicemos) conforman un grupo en el sentido considerado. Es necesario, como en el caso Hacienda Brasil Verde, que haya evidencia empírica y analítica que permita vincular pobreza y derechos humanos.

En la sentencia de la Corte IDH del caso Hacienda Brasil Verde se consideró que las víctimas concretas e individualizadas del caso pertenecían a un grupo cuya pobreza los colocaba en situación de vulnerabilidad y discriminación estructural histórica. Esa vulnerabilidad por pobreza era causa de las violaciones de derechos humanos sufridas. En tanto el Estado conocía la existencia del grupo, su vulnerabilidad y discriminación, así como el riesgo cierto e inmediato de la violación de sus derechos, incurrió en responsabilidad al no impedir las vulneraciones de derechos efectivamente acontecidas en relación con la violación del principio de igualdad y no discriminación en razón de la posición económica.

Este razonamiento jurídico nos permite concluir la posibilidad de vislumbrar los estándares que pueden llevar al Tribunal Interamericano a responsabilizar a un Estado de situaciones de pobreza causantes de violaciones de derechos humanos. En concreto, podemos afirmar que el Estado incurre en responsabilidad internacional por violación de derechos (aun siendo cometida por terceros) en relación al principio de igualdad y no discriminación, al faltar a su deber de garantía, si: a) se determina la existencia de un grupo de pobres; b) ese grupo sufre discriminación estructural como grupo vulnerable; c) dicha situación constituye un riesgo real e inmediato de violación de derechos humanos; d) el Estado conoce esa situación, y e) se produce violación de derechos humanos con causa en esa situación porque el Estado, debiendo proteger a los que sabía que estaban en riesgo, no lo hizo.

85 Véase: Doz Costa, Fernanda, op. cit., y Chinchilla Fernando et al., op. cit. 
Esta revista forma parte del acervo de la Biblioteca Jurídica Virtual del Instituto de Investigaciones Jurídicas de la UNAM

Queremos cerrar recordando que "erradicar la pobreza está en el corazón de la Agenda 2030, y también lo está el compromiso de no dejar a nadie atrás", de acuerdo con las palabras de Achim Steiner, administrador del PNUD. ${ }^{86}$ Si nos preguntamos “¿por qué tenemos que seguir intentándolo incluso cuando el reto parece abrumador?”, encontramos la respuesta en las expertas sobre la pobreza Baneerje y Dunflo: porque "es posible conseguir un avance muy significativo en la lucha contra el mayor problema del mundo mediante la acumulación de una serie de pequeños pasos, cada uno de ellos bien pensado, probado cuidadosamente y realizado con criterio". ${ }^{87}$

\section{BIBLIOGRAFÍA}

Aguirre Castro, Pamela Juliana, "Los derechos económicos, sociales y culturales a la luz de la jurisprudencia de la Corte Interamericana de Derechos Humanos", Revista Interamericana de Derechos Humanos, vol. 67, 2018.

AÑón, María José, "Derechos sociales: inconsistencias de una visión compartimentada”, en Varios autores, Teoría de la justicia y derechos fundamentales. Estudios en homenaje al profesor Gregorio Peces-Barba, Madrid, Dykinson, 2008.

ARCOS RAmírez, Federico, "Globalización, pobreza y esclavitud contemporánea: una mirada cosmopolita”, en PÉREZ AlONSO, Esteban (dir.), El derecho ante las formas de esclavitud, Valencia, Tirant lo Blanch, 2017.

BANERJEe, Abhijit y DuFlo, Esther, Repensar la pobreza. Un giro radical en la lucha contra la desigualdad global, Bogotá, Taurus, 2012.

Barrere, Ma. Ángeles (Maggy), "Martha A. Fineman y la igualdad jurídica: ¿vulnerabilidad o subordiscriminación?”, Cuadernos Electrónicos de Filosofía del Derecho, núm. 34, 2016.

BAYEBSKY, Anne F., "El principio de igualdad y no discriminación en el derecho internacional", Human Rights Law Journal, vol. 11, núms. 1-2, 1990.

86 Disponible en: http://www.undp.org/content/undp/es/home/sustainable-development-goals. html.

87 Banerjee, Abhijit y Duflo, Esther, Repensar la pobreza. Un giro radical en la lucha contra la desigualdad global, Bogotá, Taurus, 2012, p. 33. 
Esta revista forma parte del acervo de la Biblioteca Jurídica Virtual del Instituto de Investigaciones Jurídicas de la UNAM

DOI: httpa//dx_doi_org/10.22201/iij_24487872e_2020.20.14474

Butler, Judith, Precarious Life: The Powers of Mourning and Violence, Londres, Verso, 2004.

CHINCHILlA, Fernando et al., "Pobreza y derechos humanos: hacia la definición de parámetros conceptuales desde la doctrina y acciones del sistema interamericano", en Autores varios, ¿Quién responde por los derechos humanos de las poblaciones más pobres en América Latina y El Caribe? Democracia vs. Desigualdad (2007-2011), San José, Instituto Interamericano de Derechos Humanos, 2012.

COMISIÓN INTERAMERICANA DE DERECHOS HuMANOS, Informe sobre pobreza $y$ derechos humanos en las Américas, OEA/Ser.L/V/II.164. Doc. 147, 2017.

COURTIS, Christian, "Dimensiones conceptuales de la protección legal contra la discriminación”, Revista Derecho del Estado, núm. 24, julio de 2010. CuÉllar M., Roberto, "Los derechos humanos de los más pobres: una ruta por construir en el sistema interamericano", Revista del Instituto Interamericano de Derechos Humanos, núm. 48, julio-diciembre de 2008.

Doz CosTA, Fernanda, "Pobreza y derechos humanos: desde la retórica a las obligaciones legales. Una descripción crítica de los marcos conceptuales”, Sur. Revista Internacional de Derechos Humanos, núm. 9, 2008.

DuLITZKy, Ariel E., "Pobreza y derechos humanos en el Sistema Interamericano. Algunas aproximaciones preliminares, Revista del Instituto Interamericano de Derechos Humanos, núm. 48, julio-diciembre, 2008.

ESTUPIÑÁN-SILVA, Rosmerlin, "La vulnerabilidad en la jurisprudencia de la Corte Interamericana de Derechos Humanos: esbozo de una tipología”, en Burgorgue-LARsen, Laurence et al. (coords.), Derechos humanos y políticas públicas, Barcelona, Red de Derechos Humanos y Educación Superior, 2014.

FELIPE BELTRÃO, Jane et al., "Prólogo" a Derechos humanos de los grupos vulnerables, Barcelona, Red de Derechos Humanos y Educación Superior, 2014.

FERRAJOLI, Luigi, "La igualdad y sus garantías", en RuIZ, Alfonso y MACÍA Morillo, Andrea (eds.), Desafíos de la igualdad, desafíos a la igualdad, Madrid, UAM y BOE, 2009.

FERRER MAC-GREGOR, Eduardo, La justiciabilidad de los derechos económicos, sociales, culturales y ambientales en el sistema interamericano de derechos humanos, México, UNAM y CNDH, 2017.

Fineman, Martha A., "Equality, Autonomy, and the Vulnerable Subject in Law and Politics", en Fineman, M. A. \& GreAr, A. (eds.), Vulnerability. 
Esta revista forma parte del acervo de la Biblioteca Jurídica Virtual del Instituto de Investigaciones Jurídicas de la UNAM

Reflections on a New Ethical Foundation for Law and Politics, Ashgate, Farnham/Burlington, 2013.

Fineman, Martha A., "The Vulnerable Subject: Anchoring Equality in the Human Condition”, Yale Journal of Law \& Feminism, vol. 20, núm. 1, 2008. FISS, Owen, "Grupos y la cláusula de la Igual Protección”, en GARGARELLA, Roberto (comp.), Derecho y grupos desaventajados, Barcelona, Gedisa, 1999.

JimENA QUESADA, Luis, "La protección de los grupos vulnerables por el Consejo de Europa”, en SAnz Caballero, Susana (ed.), Colectivos vulnerables y derechos humanos. Perspectiva internacional, Valencia, Tiran lo Blanch, 2010.

NACIONES UnIDAS, Renovación de las naciones unidas: un programa de reforma. Informe del Secretario General, A/51/95014 de julio, 1997.

NikKen, Pedro, "Los sistemas internacionales de protección de los derechos humanos: la perspectiva del acceso a la justicia y la pobreza", Revista del Instituto Interamericano de Derechos Humanos, núm. 48, julio-diciembre, 2008.

PARRA, Oscar, "Derechos humanos y pobreza en el sistema interamericano”, Revista del Instituto Interamericano de Derechos Humanos, núm. 56, 2012.

PRIETO SANChís, Luis, "Los derechos sociales y el principio de igualdad sustantiva”, Revista del Centro de Estudios Constitucionales, núm. 22, 1995.

Rivera Basulto, Marcela Cecilia, "Justiciabilidad directa de los derechos económicos, sociales, culturales y ambientales. Después de Lagos del Campo, ¿qué sigue?”, Revista Interamericana de Derechos Humanos, vol. 67, 2018.

SABA, Roberto, Pobreza, derechos y desigualdad estructural, México, Suprema Corte de Justicia de la Nación, Tribunal Electoral del Poder Judicial de la Federación, Instituto Electoral del Distrito Federal, 2012.

SAHuí, Alejandro, "Derechos humanos y grupos desaventajados en el marco del Estado constitucional”, Perspectivas Internacionales, vol. 11, núm. 1, 2015.

YOunG, Iris Marion, "The Gendered Cycle of Vulnerability in the Less Developed World", en SATZ, D. y REICH, R. (eds.), Toward a Humanist Justice: The Political Philosophy of Susan Moller Okin, Oxford, Oxford University Press, 2009. 